\title{
Variability of Vomitoxin in Truckloads of Wheat in a Wheat Scab Epidemic Year
}

\author{
L. P. Hart, Department of Botany and Plant Pathology, and O. Schabenberger, Department of Crop and Soil Sci- \\ ences, Michigan State University, East Lansing 48824
}

\begin{abstract}
Hart, L. P., and Schabenberger, O. 1998. Variability of vomitoxin in truckloads of wheat in a wheat scab epidemic year. Plant Dis. 82:625-630.

Wheat scab, caused by Gibberella zeae, has been a serious disease in parts of the Midwest. One factor contributing to the importance of wheat scab is the contamination of grain by the mycotoxin vomitoxin (deoxynivalenol, DON), a toxic secondary metabolite. The U.S. Food and Drug Administration advisory levels for vomitoxin in wheat and wheat products require an accurate and precise assessment of vomitoxin concentration. In this study, randomly collecting probes of wheat from individual trucks and analyzing the ground wheat from each probe produced significantly less variability than subsampling and analyzing $50 \mathrm{~g}$ of whole kernels from the probes. The variability introduced by subsampling the probes and analyzing $50 \mathrm{~g}$ of whole kernels affects the precision and confidence of vomitoxin estimates. Tables of confidence intervals were developed for different sampling and subsampling patterns. To be $95 \%$ certain that the true vomitoxin concentration does not exceed the sample estimate by $1 \mu \mathrm{g} / \mathrm{g}$, analyzing either four individual probes or $5-12 \%$ subsamples of these probes would be sufficient. To increase the accuracy to about $0.5 \mu \mathrm{g} / \mathrm{g}$, either an analysis of seven probes or a 5-12\% subsample of 10 probes would be necessary, based on a one-sided confidence interval.
\end{abstract}

Wheat scab, caused by Gibberella zeae, has been a serious disease in many wheatproducing areas of the Midwest since 1991 (7). In 1996, Michigan, Ohio, and Indiana experienced the worst wheat scab epidemic of this century. Increasing production of corn (also a host of G. zeae) under conservation tillage and weather patterns that favor disease development are thought to be factors contributing to the importance of this disease $(4,7,8)$. The concept of wheat scab as an emerging disease of importance and economic impact in the Midwest was recently reviewed (7).

One factor contributing to the importance of wheat scab is the contamination of the grain with vomitoxin (deoxynivalenol, DON), a toxic secondary metabolite produced by $G$. zeae during the infection process (4). Because of its mammalian toxicity (9), the U.S. Food and Drug Administration (FDA) has issued advisory levels for vomitoxin in wheat and wheat products as follows: $1 \mu \mathrm{g}$ of vomitoxin per gram of bran, flour, and germ intended for human consumption; $10 \mu \mathrm{g}$ of vomitoxin per gram of grain and grain by-products destined for ruminating beef and feedlot cattle older than 4 months and for chickens, with the added recommendation that these ingredients not exceed $50 \%$ of the

Corresponding author: L. P. Hart

E-mail: HartL@pilot.msu.edu

Accepted for publication 3 February 1998.

Publication no. D-1998-0323-01R

(C) 1998 The American Phytopathological Society diet of cattle or chickens; and $5 \mu \mathrm{g}$ of vomitoxin per gram of grain and grain byproducts destined for swine and all other animals, with the added recommendation that these ingredients not exceed $20 \%$ of the diet of swine and $40 \%$ of the diet of other animals.

The vomitoxin advisory issued by the FDA prompted the wheat industry to initiate testing procedures at most points in the wheat-handling chain, i.e., elevators, millers, and processors. Food safety issues make it imperative to estimate vomitoxin concentrations in grain accurately and precisely. Whereas accuracy can be ensured by proper analytical techniques combined with a method of probability sampling from trucks of grain and/or the milled stream, precision is highly dependent on the actual sampling strategy and intensity. Options are i) probes that take samples of whole kernels at random from a truckload of grain followed by analysis of entire probes and ii) analysis of subsamples taken from such probes. Alternatively, the grain collected in probes can be milled, and various amounts of milled wheat can then be extracted from the stream and serve as a sample. Concerns about proper sampling methods and their effect on the precision of vomitoxin assessments in grain led to this study.

Past work on aflatoxin variability focused on toxin concentrations in kernels of shelled peanuts $(11,13,14)$ and corn $(12)$. Variability was estimated as a function of the mean aflatoxin concentration based on the negative binomial distribution. The agreement between aflatoxin concentrations in kernels of shelled peanuts and the negative binomial probability distribution was first established by Whitaker et al. (13). A Monte Carlo simulator (14) and sample data from corn and (11) and peanuts (13) were used in combination with variance component models to estimate the variability of aflatoxin contamination. The negative binomial distribution as a sample model describes the process of independently sampling kernels until a given number of contaminated kernels is found-a process known as sequential sampling in, e.g., entomology (5). The probability that any individual kernel in a lot is contaminated is constant. Under these assumptions, the relationship between the number of kernels sampled and their variability is functional and can be estimated. As a model for the spatial distribution of a random variable, it can be used to represent spatial aggregation, in contrast to a process which distributes contaminated kernels completely at random $(2,3)$. To describe vomitoxin means and variability in wheat, the negative binomial sampling model is unattractive, since sampling is not performed sequentially. Instead, samples are typically taken by inserting metal probes in grain loaded on trucks. Rather than emphasizing a discrete sampling model, this study treated vomitoxin concentration in grain as a continuously varying phenomenon, and the sample data were used to estimate variability due to the components of the sampling and analysis process.

\section{MATERIALS AND METHODS}

Samples of wheat were collected at three elevators and from a total of 14 trucks containing newly harvested wheat. Samples were collected by inserting a metal probe, approximately $2 \mathrm{~m}$ long and $3.5 \mathrm{~cm}$ in outside diameter, at random into the truckload. Ten individual probes from each truck were collected and bagged separately. The amount of grain collected per probe varied between 500 and 800 g. From five trucks chosen at random, five 50-g subsamples of whole kernels were collected from each of the 10 probes. The remaining grain was milled with a Romer mill (Romer Labs, Union, Missouri) at the finest setting to produce a mixture of flour and bran. Main stream probes (probe samples) and a 5-12\% continuous substream (5$12 \%$ substream samples) were extracted from the milled stream.

Each of the 50-g samples of whole wheat was ground in a coffee grinder (Mr. Coffee model IDS 50) and extracted for $3 \mathrm{~min}$ with 5 volumes of distilled water. A $15-\mathrm{ml}$ aliquot was centrifuged at $4 \times 10^{3} \times g$ for 
10 min to separate the solids. All of the grain milled in the Romer mill, the probe samples, and the 5-12\% substream samples were extracted in 5 volumes of distilled water for $5 \mathrm{~min}$, and then a $15-\mathrm{ml}$ aliquot was centrifuged as described above. All analyses were done by enzyme-linked immunosorbent assay (ELISA) (1). The Veratox Vomitoxin Quantitative ELISA (Neogen, Lansing, Michigan) was used according to the manufacturer's directions to determine vomitoxin concentrations in the grain. A single extraction was made for each sample; however, three aliquot samples from the extract supernatant were used to determine the concentration of vomitoxin. Vomitoxin standard equivalents were run on each 12-well strip to reduce variability between strips. Absorbance readings at $650 \mathrm{~nm}$ were made with a Bio-Tek 308 ELISA microplate reader after color development.

Statistical analysis. The main purpose of the statistical analysis in this study was

Table 1. Vomitoxin concentration in ground wheat samples and average sample weights

\begin{tabular}{|c|c|c|c|c|}
\hline \multirow[b]{2}{*}{$\begin{array}{l}\text { Truck } \\
\text { no. }\end{array}$} & \multicolumn{2}{|l|}{ Bulk samples } & \multicolumn{2}{|c|}{ Substream samples } \\
\hline & $\begin{array}{l}\text { Vomitoxin concn }(\mu \mathrm{g} / \mathrm{g} \text { of } \\
\text { grain), mean } \pm \text { SD }\end{array}$ & Avg wt (g) & $\begin{array}{l}\text { Vomitoxin concn ( } \mu \mathrm{g} / \mathrm{g} \text { of } \\
\text { grain), mean } \pm \mathrm{SD}\end{array}$ & Avg wt (g) \\
\hline 1 & $10.6 \pm 1.55$ &.$^{\mathrm{a}}$ & $11.5 \pm 1.44$ & \\
\hline 2 & $11.1 \pm 0.86$ & 357.6 & $11.6 \pm 0.86$ & 13.7 \\
\hline 3 & $0.07 \pm 0.22$ & 360.4 & $0.00 \pm 0.00$ & 41.5 \\
\hline 4 & $3.61 \pm 0.96$ & 260.5 & $1.99 \pm 1.42$ & 31.4 \\
\hline 5 & $0.00 \pm 0.00$ & 376.4 & $0.27 \pm 0.42$ & 45.4 \\
\hline 6 & $4.28 \pm 0.80$ & 336.4 & $4.95 \pm 0.82$ & 36.5 \\
\hline 7 & $6.40 \pm 0.48$ & 173.1 & $8.56 \pm 0.51$ & 17.9 \\
\hline 8 & $0.89 \pm 0.42$ & 229.9 & $0.39 \pm 0.51$ & 27.5 \\
\hline 9 & $3.22 \pm 0.76$ & 187.4 & $2.97 \pm 0.98$ & 22.3 \\
\hline 10 & $0.99 \pm 0.76$ & 209.5 & $0.22 \pm 0.40$ & 27.6 \\
\hline 11 & $4.81 \pm 1.10$ & 163.6 & $4.06 \pm 0.87$ & 23.5 \\
\hline 12 & $10.5 \pm 0.87$ & 326.1 & $8.94 \pm 1.26$ & 40.0 \\
\hline 13 & $11.9 \pm 0.41$ & 242.0 & $11.4 \pm 1.14$ & 36.4 \\
\hline 14 & $11.7 \pm 0.99$ & 280.8 & $11.3 \pm 0.76$ & 43.5 \\
\hline
\end{tabular}

a Not available. to determine vomitoxin concentration variability due to differences among probes from a single truck and differences within probes as a result of subsampling. Another question of interest was whether analysis of the milled grain from the probe samples and analysis of the subsamples constituting $5-12 \%$ of the milled grain from the probe would lead to similar conclusions regarding vomitoxin concentration and variability. The dependence of this comparison and variance estimates on the actual weight of the samples was also investigated, because the samples varied considerably in weight (Table 1). Estimation of the variance components was based on a nested linear mixed model (10) for the 50-g subsamples with random effects for probe and subsample variability. The probe-to-probe variance of the milled samples and of the 5-12\% subsamples followed a simple one-way classification. For both analyses a truck main effect was included to adjust for differences in vomitoxin concentration among trucks. Analyses of the 50-g subsamples, the probe samples, and the $5-12 \%$ subsamples were conducted separately; however, data from the probe samples and the 5-12\% subsamples were combined to increase the efficiency and power of variance component estimation. The SAS system for mixed models (6) was used to carry out restricted maximum

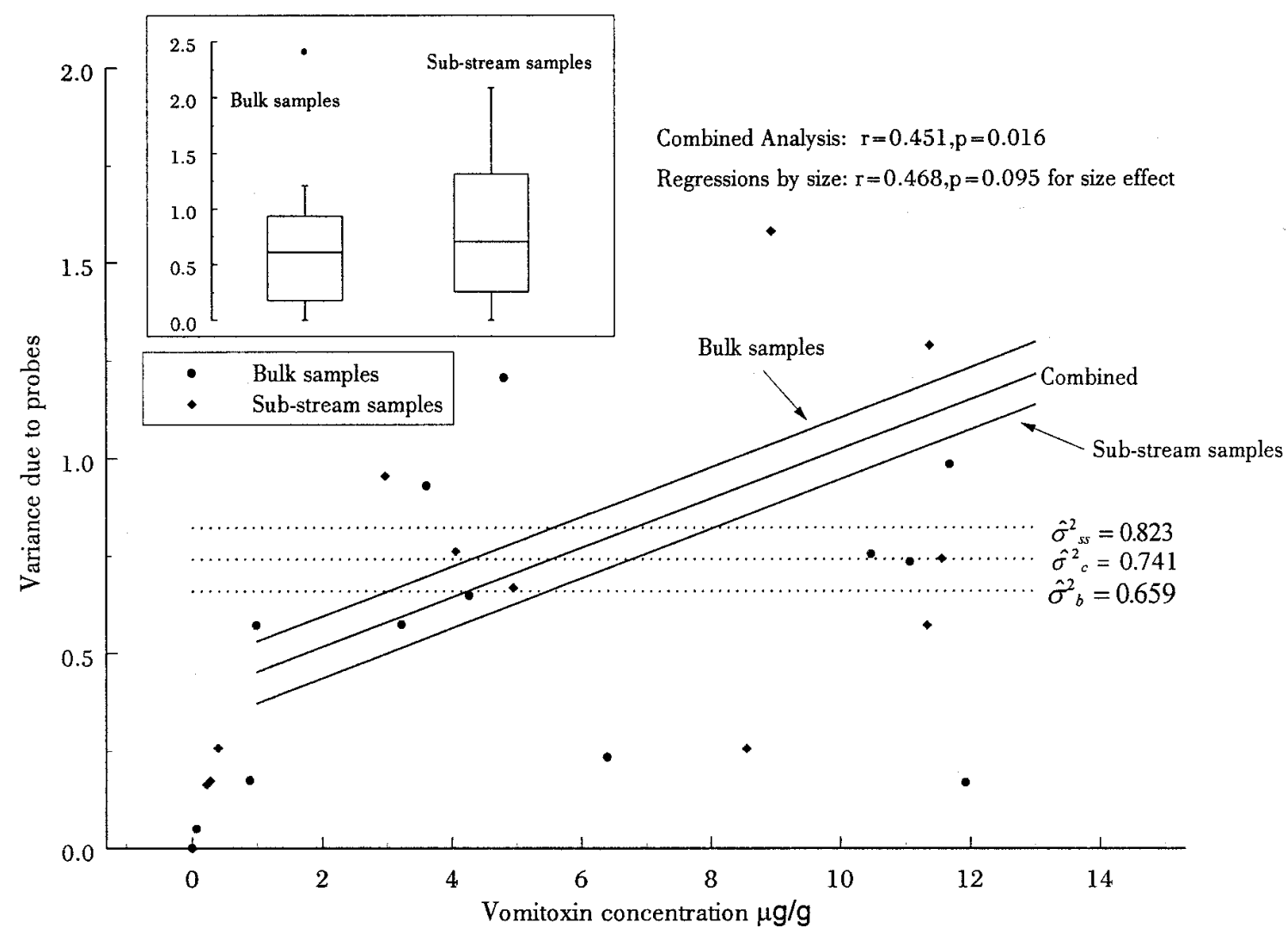

Fig. 1. Variance component estimates due to random sampling of probes and their dependence on vomitoxin concentration. Insert: Box plots of variances of bulk and substream samples. The horizontal dotted lines represent variance component estimates for probes $\left(\hat{\sigma}_{\mathrm{b}}^{2}\right), 5-12 \%$ subsamples $\left(\hat{\sigma}_{\mathrm{ss}}^{2}\right)$, and combined samples $\left(\hat{\sigma}_{\mathrm{c}}^{2}\right)$ in the absence of concentration effects. 
likelihood estimation of the variance components.

The dependence of the variance components on vomitoxin concentration was investigated through linear regression methods.

\section{RESULTS}

Stream samples. Table 1 lists the sample mean vomitoxin concentrations and standard deviations for the 14 truckloads of grain. The sample means ranged from 0.00 to $11.9 \mu \mathrm{g} / \mathrm{g}$ for the probe samples and 0.00 to $11.6 \mu \mathrm{g} / \mathrm{g}$ for the $5-12 \%$ substream samples. Figure 1 depicts the associated variance component estimates. Variances were dependent on the mean vomitoxin concentration (Fig. 1). Inserted box plots in Figure 1 show reasonably symmetric distributions of the variance estimates, which makes it possible to model the trend with changes in vomitoxin concentration on this scale. The linear regression model for both sizes of stream samples combined had a significant slope of $0.064(p=0.016)$, and estimating separate trends for the probe samples and the 5-12\% subsamples produced nonsignificant improvement ( $p=$ 0.095). The estimated model for the combined data is

$$
\hat{\sigma}^{2}=0.389+0.064 * V x
$$

where $\hat{\sigma}^{2}$ is the estimated variance component due to probes and $V x$ is vomitoxin concentration (in $\mu \mathrm{g} / \mathrm{g}$ ). This relationship can be used to derive the precision of vomitoxin estimation, and (on the assumption that the component does not depend on the number of probes being sampled) confidence intervals can be derived depending on anticipated vomitoxin concentrations. Quadratic and higher-order trends were not significant ( $p=0.18$ for the quadratic trend), and the additional adjustment for differences in actual sample weight also did not improve the variance fit $(p=0.51)$.

The effect of vomitoxin concentration on the width of one-sided $95 \%$ confidence intervals was small when more than four probes per truck were sampled (Fig. 2). The width of the one-sided $95 \%$ confidence interval for the mean vomitoxin concentration ranged from $0.79(1 \mu \mathrm{g} / \mathrm{g})$ to $1.33(14 \mu \mathrm{g} / \mathrm{g})$ for four probes. Reducing the sample size to fewer than four probes per truck had a dramatic effect. For three probes the width of the one-sided $95 \%$ confidence interval ranged from 1.13 (1 $\mu \mathrm{g} / \mathrm{g})$ to $1.91(14 \mu \mathrm{g} / \mathrm{g})$, and for only two probes the range was $3.00(1 \mu \mathrm{g} / \mathrm{g})$ to 5.05 $(14 \mu \mathrm{g} / \mathrm{g})$. For example, if the analysis of three probes sampled at random from a single truck indicates a concentration of 3 $\mu \mathrm{g} / \mathrm{g}$, one can be $90 \%$ confident that the true concentration is within $3 \pm 1.28 \mu \mathrm{g} / \mathrm{g}$ $=[1.72,4.28] \mu \mathrm{g} / \mathrm{g}$ of the sampled vomitoxin concentration. At the same level of confidence, for four probes the interval covering the true concentration is $3 \pm 0.90$ $\mu \mathrm{g} / \mathrm{g}=[2.10,3.90] \mu \mathrm{g} / \mathrm{g}$.
Albeit significant, the variance in milled grain changed slowly with the vomitoxin level. If no prior knowledge about the level of contamination is available, the overall variance component estimates can be used to construct confidence intervals. The variance component estimates were $\hat{\sigma}_{\mathrm{ss}}^{2}=0.823$ for the 5-12\% subsamples and $\hat{\sigma}_{\mathrm{b}}^{2}=0.659$ for the probe samples (Fig. 1). The variance component estimate combining both data is 0.741 . These estimates were based on 280 observations and were derived by restricted maximum likelihood. In addition, the variability in vomitoxin due to differences in sample weight was significant when the variance components were estimated across vomitoxin levels (Table 2 ). The relative magnitude of the probe samples and the 5-12\% subsamples variability was affected little by the weight

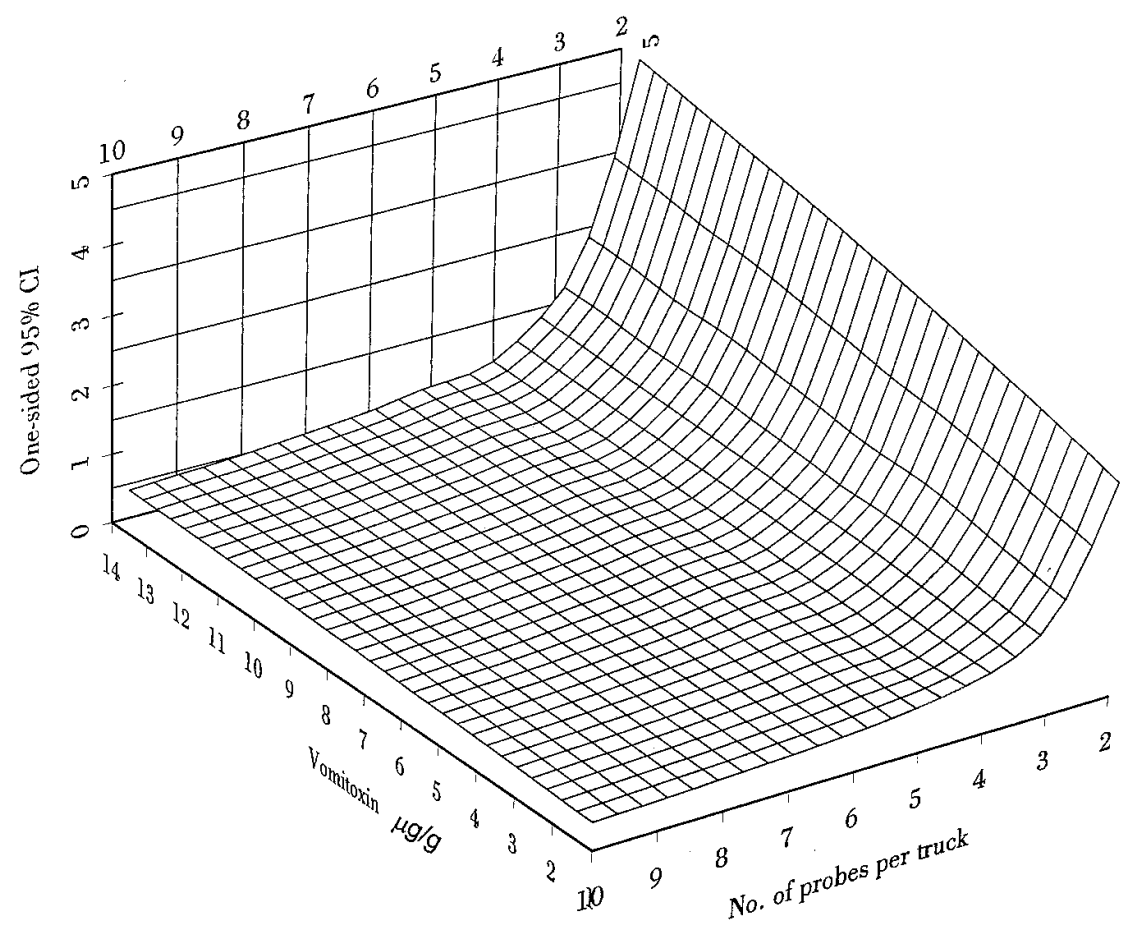

Fig. 2. One-sided $95 \%$ confidence intervals (CI) based on the model $\hat{\sigma}^{2}=0.389+0.064 * V x$ as a function of the number $(r)$ of probes being sampled at random from a single truck. Confidence intervals are based on $r-1$ degrees of freedom.

Table 2. Restricted maximum likelihood estimates of variance components (in $\mu \mathrm{g}^{2} / \mathrm{g}^{2}$ ) of vomitoxin concentration in stream samples with and without adjustment for the weight of the sample

\begin{tabular}{|c|c|c|c|c|}
\hline & \multicolumn{2}{|c|}{ Without weight adjustment } & \multicolumn{2}{|c|}{ With weight adjustment } \\
\hline & Estimate & $p$ Value & Estimate & $p$ Value \\
\hline Probe samples (300 g) & 0.660 & 0.0001 & 0.538 & 0.0001 \\
\hline $\begin{array}{l}5-12 \% \text { Substream sam- } \\
\text { ples }(13.7-45.4 \mathrm{~g})\end{array}$ & 0.823 & 0.0001 & 0.725 & 0.0001 \\
\hline
\end{tabular}

Table 3. Widths of the $95 \%$ confidence intervals for two-sided and one-sided confidence bounds for mean vomitoxin concentration ( $\mu \mathrm{g} / \mathrm{g}$ of grain)

\begin{tabular}{|c|c|c|c|c|c|c|}
\hline \multirow{2}{*}{$\begin{array}{l}\text { No. of } \\
\text { probes }(k)\end{array}$} & \multicolumn{3}{|c|}{ Probe samples } & \multicolumn{3}{|c|}{ 5-12\% Substream samples } \\
\hline & Two-sided ${ }^{a}$ & One-sided $^{a}$ & True $^{b}$ & Two-sided ${ }^{a}$ & One-sided $^{\mathrm{a}}$ & True $^{b}$ \\
\hline 2 & 13.18 & 3.27 & 2.03 & 15.30 & 3.80 & 2.36 \\
\hline 3 & 3.64 & 1.24 & 1.66 & 4.23 & 1.44 & 1.93 \\
\hline 4 & 2.33 & 0.86 & 1.44 & 2.71 & 1.00 & 1.67 \\
\hline 5 & 1.82 & 0.70 & 1.29 & 2.11 & 0.81 & 1.49 \\
\hline 6 & 1.54 & 0.60 & 1.17 & 1.79 & 0.70 & 1.36 \\
\hline 7 & 1.36 & 0.54 & 1.09 & 1.57 & 0.63 & 1.26 \\
\hline 8 & 1.23 & 0.49 & 1.02 & 1.42 & 0.57 & 1.18 \\
\hline 9 & 1.13 & 0.45 & 0.96 & 1.31 & 0.53 & 1.11 \\
\hline 10 & 1.05 & 0.43 & 0.91 & 1.22 & 0.49 & 1.06 \\
\hline
\end{tabular}

a Values derived on the assumption that $k$ probe samples were taken from a single truck, with the variance estimates given in Table 2.

b Width of the $95 \%$ confidence interval on the assumption that the values in Table 2 express true variability. 
adjustment. Probe-to-probe sample variability is 74 and $80 \%$ of the variability of the $5-12 \%$ subsamples, for the weightadjusted and unadjusted data, respectively.

Table 4. Mean vomitoxin concentration ( $\mu \mathrm{g} / \mathrm{g}$ of grain, with standard deviation in parentheses) in $50-\mathrm{g}$ samples of whole wheat kernels

\begin{tabular}{lcccccccccc}
\hline $\begin{array}{l}\text { Truck } \\
\text { no. }\end{array}$ & \multicolumn{1}{c}{ Probe no. } \\
\cline { 2 - 12 } & $\mathbf{1}$ & $\mathbf{2}$ & $\mathbf{3}$ & $\mathbf{4}$ & $\mathbf{5}$ & $\mathbf{6}$ & $\mathbf{7}$ & $\mathbf{8}$ & $\mathbf{9}$ & $\mathbf{1 0}$ \\
\hline 1 & 11.5 & 11.4 & 13.2 & $\ldots \mathrm{a}^{\mathrm{a}}$ & 11.4 & 12.4 & 9.44 & 10.8 & 10.2 & 13.9 \\
& $(0.90)$ & $(0.19)$ & $(0.47)$ & $\ldots$ & $(0.70)$ & $(0.71)$ & $(0.43)$ & $(0.76)$ & $(0.60)$ & $(0.85)$ \\
2 & 11.3 & 11.5 & 11.9 & 11.3 & 11.3 & 10.9 & 10.9 & 11.2 & 11.4 & 10.5 \\
& $(0.27)$ & $(0.43)$ & $(0.47)$ & $(0.50)$ & $(0.42)$ & $(0.15)$ & $(0.29)$ & $(0.47)$ & $(0.37)$ & $(0.38)$ \\
3 & 0.56 & 0.60 & 0.40 & 0.30 & 0.00 & 2.12 & 0.18 & 0.00 & 0.00 & 1.26 \\
& $(0.66)$ & $(1.34)$ & $(0.79)$ & $(0.67)$ & $(0.00)$ & $(0.44)$ & $(0.35)$ & $(0.00)$ & $(0.00)$ & $(2.82)$ \\
4 & 4.06 & 5.90 & 4.52 & 6.08 & 3.08 & 3.16 & 3.96 & 2.40 & 2.38 & 1.80 \\
& $(0.33)$ & $(0.73)$ & $(0.56)$ & $(0.44)$ & $(0.77)$ & $(1.25)$ & $(0.46)$ & $(0.72)$ & $(0.58)$ & $(0.44)$ \\
5 & 0.52 & 0.38 & 1.08 & 0.00 & 0.00 & 0.52 & 0.46 & 0.14 & 0.00 & 1.72 \\
& $(0.87)$ & $(0.36)$ & $(2.41)$ & $(0.00)$ & $(0.00)$ & $(1.16)$ & $(1.03)$ & $(0.22)$ & $(0.00)$ & $(1.74)$ \\
\hline
\end{tabular}

${ }^{a}$ Not available.

Table 5. Restricted maximum likelihood estimates of variance components of 50-g samples of whole kernels and relative variability of probe means due to subsampling

\begin{tabular}{|c|c|c|c|c|c|c|}
\hline \multirow{2}{*}{$\begin{array}{l}\text { Vomitoxin } \\
\text { concn }(\mu \mathrm{g} / \mathrm{g})\end{array}$} & \multirow{2}{*}{$\begin{array}{l}\text { Probe-to-probe } \\
\text { variability } \\
\left(\mu \mathrm{g}^{2} / \mathrm{g}^{2}\right)\end{array}$} & \multirow{2}{*}{$\begin{array}{c}\text { Subsampling } \\
\text { variability } \\
\left(\mu \mathrm{g}^{2} / \mathrm{g}^{2}\right)\end{array}$} & \multicolumn{4}{|c|}{$\begin{array}{l}\text { Percentage of variability due to } \\
\text { subsampling with the following } \\
\text { number of 50-g subsamples: }\end{array}$} \\
\hline & & & 1 & 5 & 10 & 15 \\
\hline $0-2$ & 0.00096 & 1.187 & 99.9 & 99.6 & 99.2 & 98.8 \\
\hline $2-8$ & 1.774 & 0.458 & 20.5 & 4.9 & 2.5 & 1.7 \\
\hline$>8$ & 0.980 & 0.287 & 22.6 & 5.5 & 2.8 & 1.9 \\
\hline Overall & 0.852 & 0.689 & 44.7 & 13.9 & 7.5 & 5.1 \\
\hline
\end{tabular}

the relative difference between the bulk samples and the substream samples, but failed to explain it entirely. There was insufficient evidence to conclude that the mean vomitoxin concentration of the milled probe samples $(5.71 \mu \mathrm{g} / \mathrm{g})$ differed significantly from that of the $5-12 \%$ subsamples $(5.57 \mu \mathrm{g} / \mathrm{g})$ taken from the milled probe samples. There was also no evidence to support the conclusion that the mean vomitoxin concentration depends on the weight of the material obtained from the stream $(r=0.028, p=0.64)$. For a sample of $k$ probes from a single truck with a sample variance estimate similar to those in Table 2 , the widths of two-sided $95 \%$ confidence limits and one-sided 95\% confidence bounds for substream and probe samples are listed in Table 3. For example, to be 95\% certain that the true vomitoxin concentration does not exceed the sample estimate by $1 \mu \mathrm{g} / \mathrm{g}$, analyzing either four individual probes or 5-12\% subsamples from these probes would be sufficient. To increase the accuracy to about $0.5 \mu \mathrm{g}$, either an analysis of seven probes or a $5-12 \%$ subsample of 10 probes would be necessary, based on a one-sided confidence interval. If one adopts the estimates in Table 2 as true variability, rather than estimating the sample variance from the probes collected on a single truck, the confidence intervals are narrower, since the uncertainty in estimating vomitoxin dispersion is eliminated (Table 3).

Whole kernel samples. Analysis of the 50-g subsamples of whole kernels showed

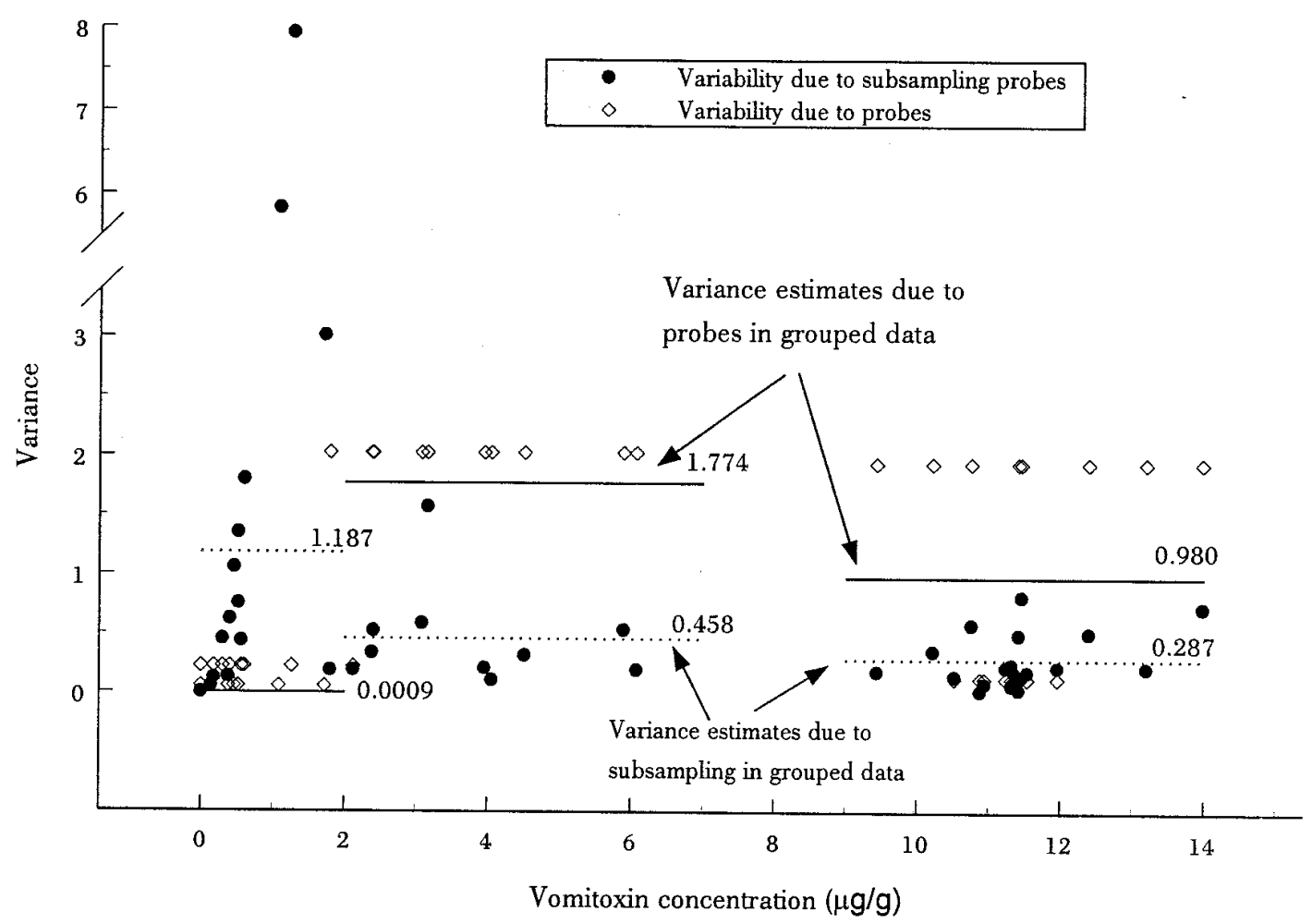

Fig. 3. Variability due to sampling probes and subsampling whole kernels (50-g subsamples) of grain from four trucks. The solid lines are estimates of the variance component due to probes by vomitoxin concentration; the dashed lines are estimates of the variance component due to subsampling. 
that the vomitoxin concentration was fairly homogeneous across probes from a single truck, while coefficients of variation (in percent) within probes ranged from 1.37 to 223.6 (Table 4). Figure 3 depicts the empirical variance component estimates due to sampling probes and subsampling whole kernels. Whereas the component due to sampling probes appears constant across a wide range of contamination levels, the probe-to-probe variability is small at low vomitoxin levels. The within-probe variability exhibits a different pattern. It is small and relatively constant for vomitoxin concentrations greater than $2-3 \mu \mathrm{g} / \mathrm{g}$. For vomitoxin levels less than $2 \mu \mathrm{g} / \mathrm{g}$ the subsampling variability can be very large. None of the analytical values was considered to be unusual.

The data do not lend themselves to modeling the dependence of the variance components on vomitoxin concentrations through a linear or nonlinear model. Instead, the data were post-stratified into three categories: $0-2 \mu \mathrm{g}, 2-8 \mu \mathrm{g}$, and more than $8 \mu \mathrm{g}$ of vomitoxin per gram. The estimates of the probe-to-probe and subsample variability are shown as horizontal lines in Figure 3. Table 5 lists the estimates of the variance components for these categories and for the combined data. Also displayed in Table 5 is the percentage of variability of the mean vomitoxin concentration in a single probe with different numbers of 50-g subsamples. When vomitoxin levels are between 0 and $2 \mu \mathrm{g} / \mathrm{g}$, the variability of $50 \mathrm{-g}$ subsamples dominates the heterogeneity among probes. At concentrations above $2 \mu \mathrm{g} / \mathrm{g}$, the variability between probes is greater than the variability of 50-g subsamples (Table 5). Overall vomitoxin variability within probes for a single 50 -g subsample is $0.852+0.689=$ $1.54 \mu \mathrm{g}^{2} / \mathrm{g}^{2}, 44.7 \%$ of which is due to variability within probes. This relatively large percentage is the result of the variability of the measurement and ELISA process as well as the lack of homogeneity of vomitoxin distribution within probes. As the number of subsamples per probe increases, the proportion of variability in the sample mean vomitoxin estimate per probe decreases. At low vomitoxin levels, for which the subsampling variability is substantial, this decrease is negligible, but it is noticeable for levels above $2 \mu \mathrm{g} / \mathrm{g}$. The effect of simultaneously increasing the number of probes is depicted in Figure 4. Box plots are shown for the distribution of the precision of the mean vomitoxin level per truckload of grain. Therefore, we conclude that increasing the number of probes is more effective than increasing subsampling intensity for 50 -g subsamples.

At very low vomitoxin concentrations, the loss of precision when subsamples are analyzed is considerable, especially if the number of probes is small (Table 6). If precision is expressed as the width of the $95 \%$ confidence interval for the mean

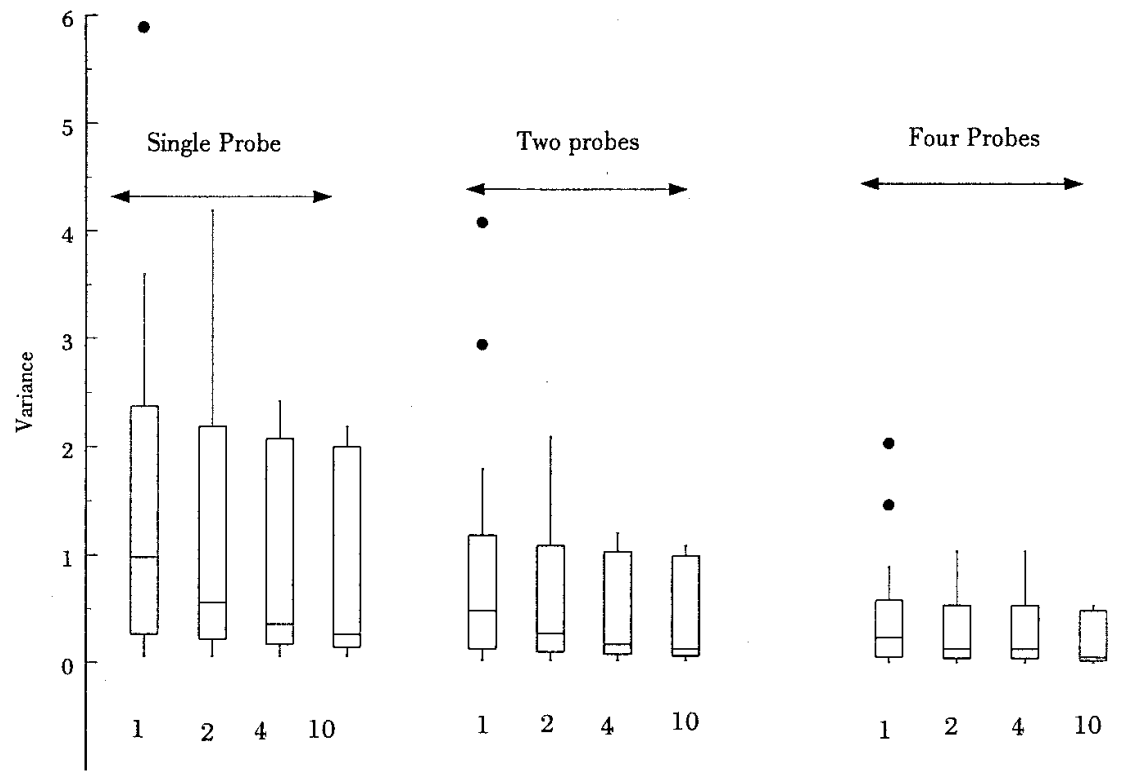

Number of 50 gram subsamples per probe

Fig. 4. Box plots of the distribution of the variance of the mean vomitoxin concentration per truckload based on the variance estimates by probes for different numbers of probes and different numbers of 50-g subsamples. The center line of each box represents the median, and each box extends from the first to the third quartile of the distribution.

Table 6. Widths of the 95\% confidence intervals (upper bound minus lower bound) for mean vomitoxin concentration ( $\mu \mathrm{g} / \mathrm{g}$ of grain) per truckload of grain for variable sampling and subsampling intensity $^{\mathrm{a}}$

\begin{tabular}{|c|c|c|c|c|c|}
\hline \multirow{2}{*}{$\begin{array}{l}\text { No. of } \\
\text { probes }(k)\end{array}$} & \multirow{2}{*}{$\begin{array}{l}\text { Vomitoxin } \\
\text { concn }(\mu \mathrm{g} / \mathrm{g})\end{array}$} & \multirow{2}{*}{$\begin{array}{l}\text { Entire } \\
\text { probe }\end{array}$} & \multicolumn{3}{|c|}{ No. of 50-g whole kernel subsamples $(r)$} \\
\hline & & & 2 & 5 & 10 \\
\hline 2 & $\begin{array}{l}0-2 \\
2-8 \\
>8 \\
\text { Overall }\end{array}$ & $\begin{array}{r}0.6 \\
23.9 \\
17.8 \\
16.6\end{array}$ & $\begin{array}{l}13.9 \\
25.4 \\
19.0 \\
19.7\end{array}$ & $\begin{array}{r}8.8 \\
24.5 \\
18.3 \\
17.9\end{array}$ & $\begin{array}{r}6.2 \\
24.2 \\
18.0 \\
17.2\end{array}$ \\
\hline 3 & $\begin{array}{l}0-2 \\
2-8 \\
>8 \\
\text { Overall }\end{array}$ & $\begin{array}{l}0.2 \\
6.6 \\
4.9 \\
4.6\end{array}$ & $\begin{array}{l}3.8 \\
7.0 \\
5.3 \\
5.4\end{array}$ & $\begin{array}{l}2.4 \\
6.8 \\
5.1 \\
4.9\end{array}$ & $\begin{array}{l}1.7 \\
6.7 \\
5.0 \\
4.8\end{array}$ \\
\hline 4 & $\begin{array}{l}0-2 \\
2-8 \\
>8 \\
\text { Overall }\end{array}$ & $\begin{array}{l}0.0 \\
2.1 \\
1.6 \\
2.9\end{array}$ & $\begin{array}{l}1.2 \\
2.3 \\
1.7 \\
3.5\end{array}$ & $\begin{array}{l}0.8 \\
2.2 \\
1.6 \\
3.2\end{array}$ & $\begin{array}{l}0.6 \\
2.1 \\
1.6 \\
3.1\end{array}$ \\
\hline 5 & $\begin{array}{l}0-2 \\
2-8 \\
>8 \\
\text { Overall }\end{array}$ & $\begin{array}{l}0.1 \\
3.3 \\
2.5 \\
2.3\end{array}$ & $\begin{array}{l}1.9 \\
3.5 \\
2.6 \\
2.7\end{array}$ & $\begin{array}{l}1.2 \\
3.4 \\
2.5 \\
2.5\end{array}$ & $\begin{array}{l}0.9 \\
3.4 \\
2.5 \\
2.4\end{array}$ \\
\hline 6 & $\begin{array}{l}0-2 \\
2-8 \\
>8 \\
\text { Overall }\end{array}$ & $\begin{array}{l}0.1 \\
2.8 \\
2.1 \\
1.9\end{array}$ & $\begin{array}{l}1.6 \\
3.0 \\
2.2 \\
2.3\end{array}$ & $\begin{array}{l}1.0 \\
2.9 \\
2.1 \\
2.1\end{array}$ & $\begin{array}{l}0.7 \\
2.8 \\
2.1 \\
2.0\end{array}$ \\
\hline 7 & $\begin{array}{l}0-2 \\
2-8 \\
>8 \\
\text { Overall }\end{array}$ & $\begin{array}{l}0.1 \\
2.5 \\
1.8 \\
1.7\end{array}$ & $\begin{array}{l}1.4 \\
2.6 \\
2.0 \\
2.0\end{array}$ & $\begin{array}{l}0.9 \\
2.5 \\
1.9 \\
1.8\end{array}$ & $\begin{array}{l}0.6 \\
2.5 \\
1.9 \\
1.8\end{array}$ \\
\hline 8 & $\begin{array}{l}0-2 \\
2-8 \\
>8 \\
\text { Overall }\end{array}$ & $\begin{array}{l}0.1 \\
2.2 \\
1.7 \\
1.5\end{array}$ & $\begin{array}{l}1.3 \\
2.4 \\
1.8 \\
1.8\end{array}$ & $\begin{array}{l}0.8 \\
2.3 \\
1.7 \\
1.7\end{array}$ & $\begin{array}{l}0.6 \\
2.3 \\
1.7 \\
1.8\end{array}$ \\
\hline 10 & $\begin{array}{l}0-2 \\
2-8 \\
>8 \\
\text { Overall }\end{array}$ & $\begin{array}{l}0.0 \\
1.9 \\
1.4 \\
1.3\end{array}$ & $\begin{array}{l}1.1 \\
2.0 \\
1.5 \\
1.6\end{array}$ & $\begin{array}{l}0.7 \\
2.0 \\
1.5 \\
1.4\end{array}$ & $\begin{array}{l}0.5 \\
1.9 \\
1.4 \\
1.4\end{array}$ \\
\hline
\end{tabular}

${ }^{\text {a }}$ It is assumed that $k$ probes are sampled from a single truck and $r 50$-g subsamples of whole kernels are taken from the probe. The variance estimates based on $k r$ observations are assumed identical to those in Table 5. 
Table 7. Accuracy and precision of enzyme-linked immunosorbent assay for vomitoxin in wheat according to the manufacturer's specifications ${ }^{\mathrm{a}}$

\begin{tabular}{llllllll}
\hline & \multicolumn{7}{c}{ Values at vomitoxin concentration of $(\boldsymbol{\mu g} / \mathbf{g}):$} \\
\cline { 2 - 8 } & $\mathbf{0 . 0 0}$ & $\mathbf{0 . 3 0}$ & $\mathbf{0 . 5 0}$ & $\mathbf{1 . 0 0}$ & $\mathbf{2 . 0 0}$ & $\mathbf{4 . 0 0}$ & $\mathbf{5 . 0 0}$ \\
\hline Sample mean & 0.13 & 0.38 & 0.55 & 0.99 & 2.00 & 3.60 & 4.50 \\
Sample variance & 0.03 & 0.08 & 0.07 & 0.05 & 0.07 & 0.31 & 0.23 \\
\hline
\end{tabular}

a Veratox Vomitoxin Quantitative ELISA (Neogen, Lansing, Michigan).

vomitoxin concentration per truckload of grain, the intervals are narrower when entire probes are analyzed, since the subsampling variability is eliminated. For vomitoxin levels above $2 \mu \mathrm{g} / \mathrm{g}$ added variability due to subsampling did not have a detrimental effect on precision if five or more 50-g subsamples were collected from each probe.

\section{DISCUSSION}

Accurate and precise assessment of vomitoxin concentration in wheat requires that a sample of wheat kernels or ground wheat be obtained and analyzed from a particular storage unit (such as a truck). The sample design must be a carefully chosen combination of probabilistic sampling strategy, such as simple random or stratified sampling, and intensity to properly represent the vomitoxin distribution and to provide precise estimates of concentrations with an appropriate level of confidence. The accuracy of vomitoxin estimates is not guaranteed by intense sampling. The sampling strategy must also be adaptive, because the spatial distribution of vomitoxin in epidemic years is likely to differ from that in nonepidemic years.

Whitaker et al. (11) found an exponential increase in total variability with increasing aflatoxin contamination of shelled peanuts. A similar conclusion cannot be drawn for Michigan wheat during the 1996 scab epidemic. Those authors also reported that subsampling variability was small relative to the sample-to-sample (probe-toprobe) variability in shelled peanuts. The results presented in Figure 3 and Table 5 show that this is not the case for vomitoxin in wheat. Substantial variability can be observed if 50-g subsamples of whole wheat kernels are obtained and analyzed. Whereas subsampling variability remains small at high levels of vomitoxin contamination, it can be quite substantial and larger than probe-to-probe variability at low levels of contamination. This fact is of importance in nonepidemic years, when the distribution of contaminated kernels in a truckload is likely to be less homogeneous than in an epidemic year. Not accounted for in our methodological approach are errors in the ELISA itself. Methodological error or measurement is larger relative to baseline contamination at concentrations of vomitoxin below $1 \mu \mathrm{g} / \mathrm{g}$ than at higher levels of contamination, according to information provided by the ELISA manufacturer (Table 7). However, as a practical consideration, the variability of vomitoxin concentrations below $1 \mu \mathrm{g} / \mathrm{g}$ is not critical with respect to FDA guidelines.

The relative homogeneity of vomitoxin in probes from the same truckload (Table 3 ) is indicative of the epidemic nature of G. zeae in 1996. However, large differences existed between trucks. If vomitoxin was noticeable in 1996, it was found in practically all probes sampled from a particular truck, whereas its absence was indicative of lack of vomitoxin contamination of the truckload. This could lead one to abandon probabilistic sampling for vomitoxin and instead to analyze single-probe samples drawn systematically. Although, on average, this may produce unbiased estimates of concentration in epidemic years, it produces highly imprecise and unreliable estimates. More importantly, in nonepidemic years vomitoxin is more likely to be unevenly distributed in a truckload of wheat, and indiscriminate sampling procedures may provide a false sense of security.

Little is known at present about the spatial patterns of vomitoxin-contaminated grain within and among sampling units and their effect on sampling accuracy. Practical considerations suggest analysis of subsamples for each probe. However, the variability introduced by subsampling and analyzing $50 \mathrm{~g}$ of whole kernels from probes can have a negative impact on the precision and confidence of vomitoxin estimates, not acceptable in practice. Further topics regarding sampling strategies that need to be addressed are i) the effect of the size of an individual sample on variability at constant sample intensity when samples are taken from the milled stream and ii) the cost-optimal (given the required precision) and precision-optimal (given the costs of sampling) combinations of probe and subsamples.

\section{LITERATURE CITED}

1. Casale, W. L., Pestka, J. J., and Hart, L. P. 1988. Enzyme-linked immunosorbent assay employing monoclonal antibody specific for deoxynivalenol (vomitoxin) and several analogs. J. Agric. Food Chem. 26:663-668.

2. Cox, D. R., and Isham, V. 1980. Point Processes. Chapman and Hall, New York.

3. Cressie, N. 1993. Statistics for Spatial Data. John Wiley and Sons, New York.

4. Hart, L. P., Pestka, J. J., and Liu, M. T. 1984 Effect of kernel development and wet periods on production of deoxynivalenol in wheat infected with Gibberella zeae. Phytopathology 74:1415-1418.

5. Jones, V. P. 1994. Sequential estimation and classification procedures for binomial counts. Pages 195-205 in: Handbook of Sampling Methods for Arthropods in Agriculture. L. P. Pedigo and G. D. Buntin, eds. CRC Press, Boca Raton, FL.

6. Littell, R. C., Milliken, G. A., Stroup, W. W., and Wolfinger, R. D. 1996. SAS System for Mixed Models. SAS Institute, Cary, NC.

7. McMullen, M., Jones, R., and Gallenburg, D. 1997. Scab of wheat and barley: A re-emerging disease of devastating impact. Plant Dis. 81:1340-1348.

8. Parry, D. W., Jenkinson, P., and McLeod, L 1995. Fusarium ear blight (scab) in small grains-A review. Plant Pathol. 44:207-238.

9. Rotter, B., Prelusky, D., and Pestka, J. 1996. Toxicology of deoxynivalenol (vomitoxin). J. Toxicol. Environ. Health 48:1-34.

10. Searle, S. R., Casella, G., and McCulloch, C. E. 1992. Variance Components. John Wiley and Sons, New York.

11. Whitaker, T. B., Dickens, J. W., and Monroe, R. J. 1974. Variability of aflatoxin test results. J. Am. Oil Chem. Soc. 51:214-218.

12. Whitaker, T. B., Dickens, J. W., and Monroe, R. J. 1979. Variability associated with testing corn for aflatoxin. J. Am. Oil Chem. Soc. 56: 789-794.

13. Whitaker, T. B., Dickens, J. W., and Wiser, E. H. 1972. Comparison of the observed distribution of aflatoxin in shelled peanuts to the negative binomial distribution. J. Am. Oil Chem. Soc. 49:590-593.

14. Whitaker, T. B., Dickens, J. W., and Wiser, E. H. 1976. Monte Carlo technique to simulate aflatoxin testing programs for peanuts. J. Am. Oil Chem. Soc. 53:545-547. 